\title{
Clinical Characteristics and Treatment Outcomes of 3 Subtypes of Achalasia According to the Chicago Classification in a Tertiary Institute in Korea
}

\author{
Ju Yup Lee, ${ }^{1}$ Nayoung Kim, ${ }^{1,2 *}$ Sung Eun Kim, ${ }^{3}$ Yoon Jin Choi, ${ }^{1}$ Kyu Keun Kang, ${ }^{1}$ Dong Hyun Oh, ${ }^{1}$ Hee Jin Kim, ${ }^{1}$ Kwung \\ Jun Park, ${ }^{1}$ A Young Seo, ${ }^{1}$ Hyuk Yoon, ${ }^{1}$ Cheol Min Shin, ${ }^{1}$ Young Soo Park, ${ }^{1,2}$ Jin-Hyeok Hwang, ${ }^{1,2}$ Jin-Wook Kim, ${ }^{1,2}$ Sook-Hyang \\ Jeong ${ }^{1,2}$ and Dong Ho Lee ${ }^{1,2}$ \\ ${ }^{1}$ Department of Internal Medicine, Seoul National University, Bundang Hospital, Seongnam, Gyeonggi-do, Korea; ${ }^{2}$ Department of Internal \\ Medicine and Liver Research Institute, Seoul National University College of Medicine, Seoul, Korea; and ${ }^{3}$ Department of Internal Medicine, \\ Kosin University College of Medicine, Busan, Korea
}

\section{Background/Aims}

Achalasia is classified into 3 types according to the Chicago classification. The aim of this study was to investigate characteristics and treatment outcomes of 3 achalasia subtypes in Korean patients.

\section{Methods}

Fifty-five patients diagnosed with achalasia based on conventional or high-resolution esophageal manometry were consecutively enrolled. Their clinical characteristics, manometric, endoscopic and esophagographic findings and treatment responses were analyzed among the 3 subtypes of achalasia.

Results

Of 55 patients, 21 (38.2\%) patients had type I, 28 (50.9\%) patients had type II and $6(10.9 \%)$ patients had type III. The median follow-up period was 22.4 (interquartile range, 3.6-67.4) months. Type III patients were older than type I and II patients (70.0 vs. 46.2 and 47.6 years, $P=0.023$ ). The width of the esophagus in type I patients was wider with more frequent bird's beak appearance on esophagogram than the other 2 types $(P=0.010$ and 0.006 , respectively). Of the 50 patients who received the evaluation for treatment response at 3 months, 7 patients (36.8\% vs. 26.9\%) were treated with pneumatic dilatation and 4 patients (21.1\% vs. 15.4\%) with laparoscopic Heller's myotomy in type I and II groups, respectively. The treatment responses of pneumatic dilatation and Heller's myotomy in type I group were 71.4 and $50.0 \%$ and in type II were 85.7 and $75.0 \%$, respectively, and all 5 patients in type III group showed good response to medical therapy.

Received: August 10, 2013 Revised: September 11, 2013 Accepted: September 11, 2013

(c) This is an Open Access article distributed under the terms of the Creative Commons Attribution Non-Commercial License (http://creativecommons. org/licenses/by-nc/3.0) which permits unrestricted non-commercial use, distribution, and reproduction in any medium, provided the original work is properly cited.

*Correspondence: Nayoung Kim, MD

Department of Internal Medicine, Seoul National University Bundang Hospital, 82 Gumi-ro, 173 Beon-gil, Bundang-gu, Seongnam, Gyeonggi-do 463-707, Korea

Tel: +82-31-787-7008, Fax: +82-31-787-4051, E-mail: nayoungkim49@empas.com

Financial support: This work was supported by the National Research Foundation of Korea (NRF) grant (No. 2011-0030001) for the Global Core Research Center (GCRC) funded by the Korea government (MSIP).

Conflicts of interest: None.

Author contributions: Ju Yup Lee analyzed and interpreted the data and wrote a manuscript. Nayoung Kim designed, organized and mediated the present study, and supervised the manuscript. Sung Eun Kim, Yoon Jin Choi collected the data. Kyu Keun Kang, Dong Hyun Oh, Hee Jin Kim, Kwung Jun Park and A Young Seo performed the statistical analysis. Hyuk Yoon, Cheol Min Shin, Young Soo Park, Jin-Hyeok Hwang, Jin-Wook Kim, Sook-Hyang Jeong and Dong Ho Lee advised design and supervised preparing manuscript. 


\section{Conclusions}

Clinical characteristics of 3 achalasia subtypes in Korean patients are consistent with other studies. Treatment outcomes are variable among 3 subtypes.

(J Neurogastroenterol Motil 2013;19:485-494)

\section{Key Words}

Esophageal achalasia; Esophageal motility disorders; Manometry

\section{Introduction}

Achalasia is a rare esophageal motility disorder with a prevalence of 10 cases per 100,000 population and an incidence of approximately 0.5 cases per 100,000 population per year. ${ }^{1,2}$ It is characterized by the absence of peristalsis and impaired relaxation of the lower esophageal sphincter (LES). Clinical symptoms of achalasia are dysphagia, regurgitation, chest pain and weight loss. The exact pathophysiology of achalasia has not been fully understood, but functional loss of myenteric plexus ganglion cells in the distal esophagus and LES, therefore causing imbalance between the excitatory and inhibitory innervation of the distal esophagus is the generally accepted mechanism. ${ }^{3,4}$

Esophageal manometry is necessary for the diagnosis of achalasia. The absence of normal peristalsis of esophageal body and incomplete relaxation of LES are its typical findings. Highresolution manometry (HRM) is more sensitive, provides more detailed information and easier to perform than conventional manometry (CM). ${ }^{5-8}$ Recently, Pandolfino et al ${ }^{9}$ described a new manometric achalasia subtype according to the HRM with pressure topography: type I, achalasia with minimal esophageal pressurization; type II, achalasia with esophageal compression; and type III, achalasia with spasm.

Previous studies based on this new classification of achalasia showed that type II is the most common subtype, and that each subtype has different clinical and manometric characteristics. Moreover, type II is associated with good treatment response, whereas type III is associated with poor treatment response, most of which have been reported in Western studies. ${ }^{9-15}$ These results suggest that each subtype could be associated with different disease mechanisms and that subtyping might play an important role in predicting treatment response. However, clinical data related with the achalasia subtype in the Korean population have been lacking. Therefore, the aim of this study was to investigate clinical characteristics, manometric results and treatment responses among the 3 achalasia subtypes in Korean patients.

\section{Materials and Methods}

\section{Patients}

Patients diagnosed with achalasia by using CM or HRM between September 2003 and July 2013 at Seoul National University Bundang Hospital were consecutively enrolled. Among 57 patients who were diagnosed with achalasia, 2 patients were excluded due to previous pneumatic dilatation (PD) or laparoscopic Heller's myotomy (LHM). Finally, the data of 55 patients were retrospectively analyzed. Forty $(72.7 \%)$ patients were diagnosed with achalasia by using $\mathrm{CM}$ and 15 patients (27.3\%) were diagnosed with achalasia by using HRM. All enrolled patients had an interview with physicians and the patients' symptoms were recorded by using planned recording formats. The symptom duration was time from the date of symptom occurrence to the interview date. The total symptom score was calculated based on the Eckardt score, ${ }^{16}$ which was the sum of each symptom score for dysphagia, regurgitation and chest pain ( 0 , absent; 1 , occasional; 2, daily; and 3, each meal), and weight loss ( 0 , no weight loss; 1 , $<5 \mathrm{~kg} ; 2,5-10 \mathrm{~kg}$; and 3, > $10 \mathrm{~kg}$ ). Patients with a history of esophageal or gastric surgery and previous pneumatic dilatation or laparoscopic Heller's myotomy were excluded. Medical or surgical treatment was considered in patients whose symptom could negatively affect daily life (daily symptom, Eckardt score $\geq 2$ ). First, calcium channel blocker (CCB) was tried, if it was not contraindicated. $\mathrm{PD}$ was performed in patients with poor response to CCB. If patients had predictors of poor response to $\mathrm{PD}$, such as young age, male, and wide esophagus, LHM was conducted with PD skipped. Also, adverse events immediately after PD brought about LHM. All patients were provided informed consent and this study was approved by the institutional review board of Seoul National University Bundang Hospital.

\section{Conventional Manometry}

An 8-channel water perfused manometry catheter (UPS-2020; Medical Measurements Systems, Enschede, The Netherlands) 
with a sleeve sensor incorporated at the distal end was inserted into the esophagus via the nose. A pull-through technique was used to determine the LES pressure. A manometer was placed in the distal esophagus so that the most distal pressure lumen was situated $3 \mathrm{~cm}$ above the LES. Basal LES pressure, residual LES pressure, esophageal body contraction amplitude and duration were assessed on ten consecutive swallows consisting of $5 \mathrm{~mL}$ of water at 20 second intervals. The distal esophageal amplitude (DEA) was measured at level of 3 and $8 \mathrm{~cm}$ above the LES. The average of both amplitudes was used as DEA.

\section{High-resolution Manometry}

An HRM with 32 solid-state sensors spaced at $1 \mathrm{~cm}$ intervals (InSIGHT ${ }^{\mathrm{TM}} \mathrm{HRiM}^{\mathrm{R}}$ system, Sandhill Scientific, Highlands Ranch, CO, USA) was used. HRM assembly was passed transnasally and positioned in order to record from the hypopharynx to the stomach. Studies were performed with the patient in the sitting position after at least 6 hours of fasting. The manometric protocol included a 5 minute-period to assess basal sphincter pressure and ten $5 \mathrm{~mL}$-water swallows. Manometric data were analyzed using the BioVIEW software (Sandhill Scientific).
Pressure readings were converted into topographic (color contour) plots to provide a continuous picture of the pressure throughout the segment considered.

\section{Manometry Analysis}

If HRM was used, analysis was performed with the BioVIEW software and the isobaric contour tool was set at $30 \mathrm{mmHg}$ to measure the pressurization front velocity. Achalasia was identified as an impaired LES relaxation during swallowing (mean integrated relaxation pressure $[\mathrm{IRP}] \geq 15 \mathrm{mmHg}$ ) and absence of normal peristalsis of esophageal body. IRP was defined as the LES relaxation pressure for 4 seconds within the relaxation window. Type I achalasia described cases with mean IRP $\geq 15 \mathrm{mmHg}$ and $100 \%$ failed peristalsis; type II achalasia was identified as mean IRP $\geq 15 \mathrm{mmHg}$, no normal peristalsis, pan-esophageal pressurization with $\geq 20 \%$ of swallows; and type III achalasia, mean IRP $\geq 15 \mathrm{mmHg}$, no normal peristalsis, preserved fragments of distal peristalsis or premature (spastic) contractions with $\geq 20 \%$ of swallows (Fig. 1). ${ }^{9}$ All CM traces were reviewed by one physician (J.Y.L.). Patients were classified as having type I achalasia when $8 / 10$ swallows elicited contractions with an amplitude $<30$
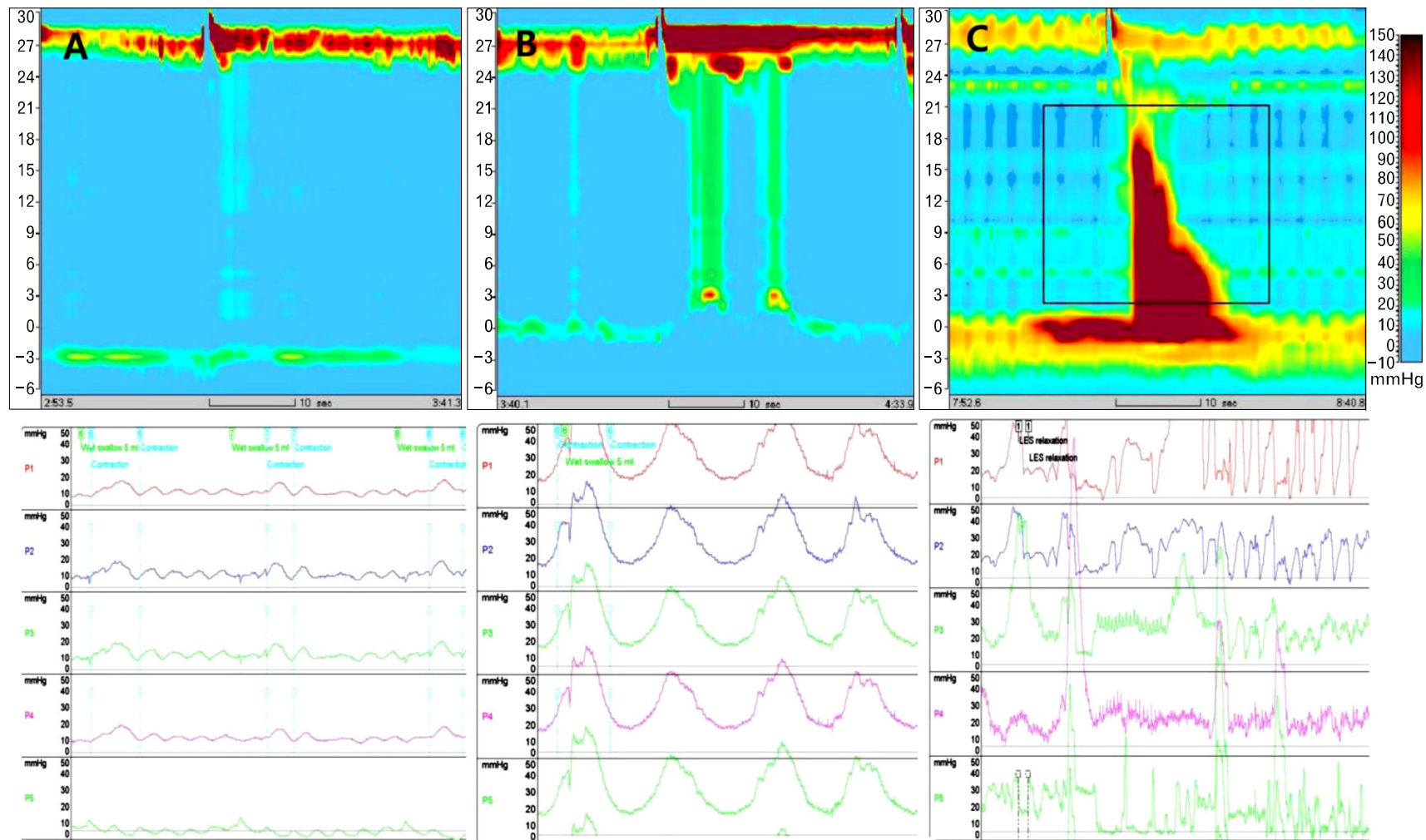

Figure 1. Three subtypes of achalasia based on the high-resolution manometry. A similar classification can be made when conventional manometry is used. Type I, achalasia with minimal esophageal pressurization (A); type II, achalasia with esophageal compression (B); type III, achalasia with spasm (C). 
$\mathrm{mmHg}$; type II achalasia when 2 or more contractions had an amplitude $>30 \mathrm{mmHg}$; and type III achalasia when at least 2 spastic waves were detected (i.e., amplitude $>70 \mathrm{mmHg}$ and duration $>6.0$ seconds) $($ Fig. 1$) .^{10}$

\section{Upper Gastrointestinal Endoscopy}

Upper gastrointestinal endoscopy (GIF H260; Olympus, Tokyo, Japan) was performed to check the food stasis or the degree of esophageal distension and to rule out secondary achalasia. All endoscopic examinations were carried out and assessed by expert endoscopists (N.K., C.M.S., Y.S.P. and D.H.L.)

\section{Barium Esophagography}

Timed barium swallow was performed in the standing position after an overnight fast. Patients were asked to drink $200 \mathrm{~mL}$ of barium solution (or as much as tolerated without regurgitation or aspiration). Recordings of the esophagus were performed at 1 , 2 and 5 minutes after the last barium swallow. The typical 'bird's beak' appearance was defined as smooth tapering of the distal esophagus with proximal dilation of the esophagus. The width of the barium column was measured 5 minutes after the last barium swallow.

\section{Treatment Response}

Short-term treatment response was evaluated 3 months after the treatment. Of 55 patients, $50(90.9 \%)$ patients completed the evaluation of short-term response, and were analyzed. Long-term treatment response was evaluated in 13 (23.6\%) patients more than 5 years after the treatment. A poor response was defined as an increased Eckardt symptom score of more than 3 after treatment ${ }^{13}$ or an aggravation of patient's subjective symptoms. A good response was defined when the Eckardt symptom scores were decreased to 3 or less after treatment ${ }^{15}$ or when the patient's subjective symptoms were improved.

\section{Statistical Methods}

Parametric continuous variables are presented as mean \pm $\mathrm{SD}$, and nonparametric variables are presented as median (interquartile range $[\mathrm{IQR}])$. Categorical variables are presented as numbers and percentages. Comparison among the 3 subtypes was performed using one way analysis of variance for parametric variables, and the Kruskal-Wallis test was performed for nonparametric variables. In cases of statistically significant difference, the post hoc Student $t$ test or Mann-Whitney $U$ test was performed with Bonferroni's correction. Categorical variables were analyzed using the Chi-square test or Fisher's exact test. $P$-values of less than 0.05 were considered statistically significant. All statistical analyses were performed using SPSS software (version 20.0; SPSS Inc, Chicago, IL, USA).

\section{Result}

\section{Patient Characteristics}

The baseline characteristics of the 55 patients are summarized in Table 1. There were 21 (38.2\%) type I achalasia patients, $28(50.9 \%)$ type II and $6(10.9 \%)$ type III. Type III patients were the oldest (70.0 years, $P=0.023$ ). Dysphagia was the most

Table 1. Baseline Characteristics of 55 Patients According to 3 Achalasia Subtypes

\begin{tabular}{|c|c|c|c|c|}
\hline & Type I & Type II & Type III & $P$-value \\
\hline Patients (n $[\%]$ ) & $21(38.2)$ & $28(50.9)$ & $6(10.9)$ & \\
\hline Age (mean $\pm \mathrm{SD}, \mathrm{yr})$ & $46.2 \pm 19.2$ & $47.6 \pm 19.8$ & $70.0 \pm 8.2^{\mathrm{a}, \mathrm{b}}$ & 0.023 \\
\hline Gender (n [\%]) & & & & 0.706 \\
\hline Male & $11(52.4)$ & $13(46.4)$ & $2(33.3)$ & \\
\hline Female & $10(47.6)$ & $15(53.6)$ & $4(66.7)$ & \\
\hline \multicolumn{5}{|l|}{ Symptoms (n [\%]) } \\
\hline Dysphagia & $20(95.2)$ & $24(88.9)$ & $4(66.7)$ & 0.145 \\
\hline Chest pain & $6(28.6)$ & $6(22.2)$ & $1(16.7)$ & 0.793 \\
\hline Regurgitation & $13(61.9)$ & $15(53.6)$ & $1(16.7)$ & 0.146 \\
\hline Weight loss & $11(55.0)$ & $10(40.0)$ & $1(20.0)$ & 0.315 \\
\hline Total Eckardt score (median [IQR]) & $5.0(3.3-7.0)$ & $4.0(3.0-6.0)$ & $3.0(2.3-3.3)$ & 0.098 \\
\hline Symptom duration (median [IQR], mo) & $24.0(7.0-48.0)$ & $24.0(8.0-36.0)$ & $12.0(3.5-78.0)$ & 0.930 \\
\hline
\end{tabular}

${ }^{\mathrm{a}} P<0.05$ vs. type I; ${ }^{\mathrm{b}} P<0.05$ vs. type II. 

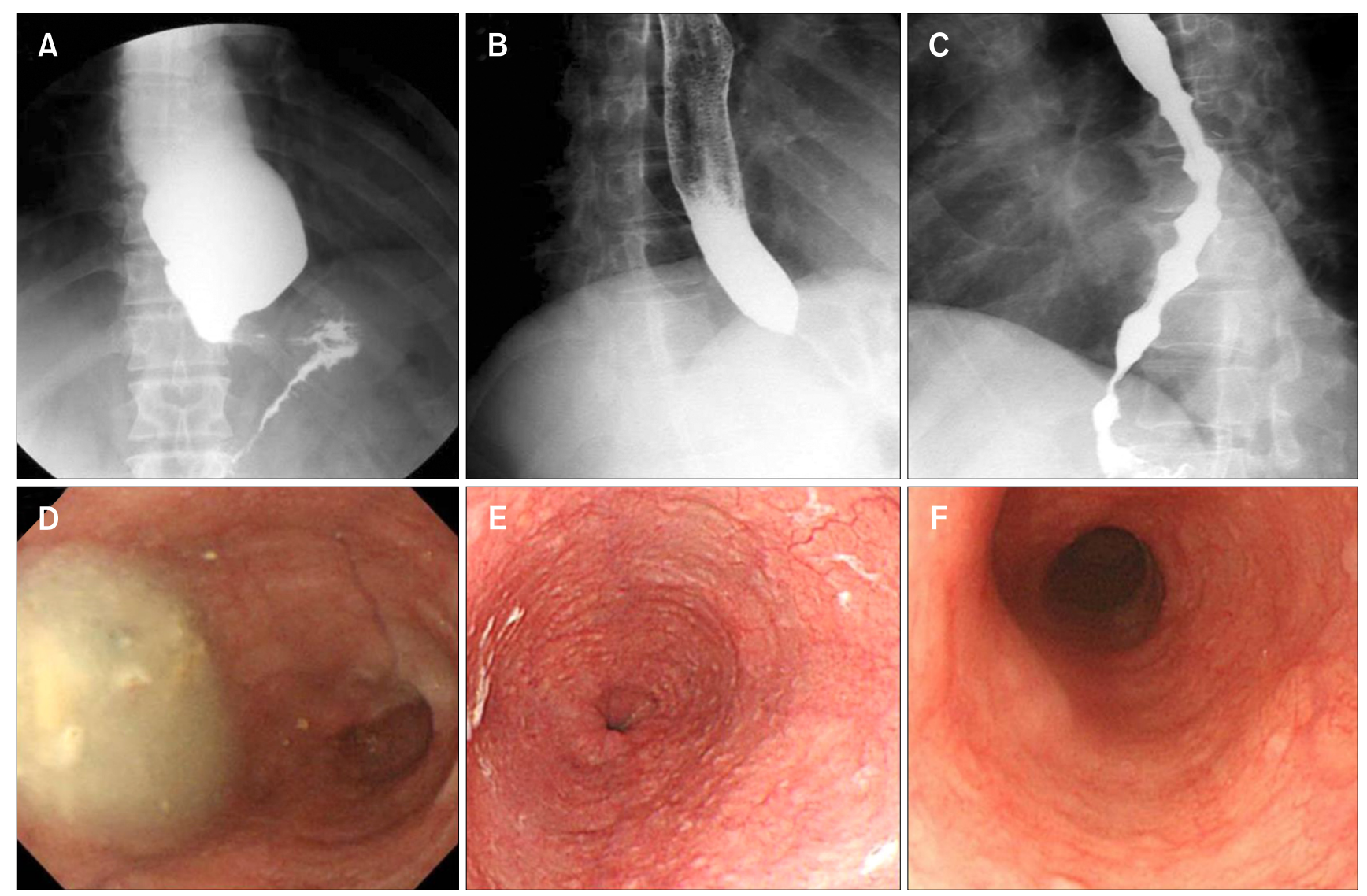

Figure 2. Representative esophagogram and upper gastrointestinal endoscopy findings of 3 achalasia subtypes (Type I - A, D; Type II - B, E; Type III - C, F). Marked dilatation of the esophagus and bird's beak appearance are noted on the esophagogram (A). Moderately dilated esophagus is noted and the proximal esophagus is filled with air which is evident by the associated esophagogram (B). The associated esophagogram for type III achalasia is often interpreted as esophageal spasm as this has an extreme corkscrew with distal contraction (C). Food stasis and flaccid esophagus are noted on the upper gastrointestinal endoscopy (D). Narrow gastroesophageal junction is noted on the upper gastrointestinal endoscopy and the scope can pass through with resistance (E). Upper gastrointestinal endoscopy findings are nearly normal in type III achalasia (F).

common symptom in type I, II and III $(95.2 \%, 88.9 \%$ and $66.7 \%$, respectively), and regurgitation was the second most common symptom $(61.9 \%, 53.6 \%$ and $16.7 \%$, respectively) in each subtype. There were no statistical differences in gender distribution, symptom duration or median follow-up period among the 3 subtypes (Table 1).

\section{Manometry, Upper Gastrointestinal Endoscopy and Esophagography}

The basal LES pressure in type III patients was higher than those of other 2 types $(P=0.004)$. The maximal esophageal pressure and DEA in type I achalasia were significantly lower than those in type II and III achalasia (all $P<0.0001$ ), There were no statistical differences in the overall length of LES $(P=$ 0.054), basal UES pressure and IRP. Type I achalasia showed marked dilatation and food stasis on upper gastrointestinal endoscopy ( $P=0.009)$ (Fig. 2D), whereas type II and III achalasia patients showed nearly normal upper gastrointestinal endoscopy (Fig. 2E and 2F). The median esophageal width was significantly wider in type I achalasia $(46.0 \mathrm{~mm})$ (Fig. 2A) compared with that in type III $(23.0 \mathrm{~mm})$ (Fig. $2 \mathrm{C})(P=0.010)$. Type I achalasia showed bird's beak appearance on esophagogram $(P=0.006)($ Fig. $2 \mathrm{~A})$ more frequently than type II (Fig. 2B) and III achalasia (Fig. 2C) (Table 2).

\section{Short-term Treatment Response}

Among 55 patients, 50 (90.9\%) patients received the evaluation for short-term response 3 months after the treatment. The median follow-up period in I, II, and III subtype was 37.0, 22.0 and 15.4 months, respectively, without statistical significance. Of 
Table 2. Manometry, Upper Gastrointestinal Endoscopy and Esophagogram Findings of 55 Patients According to 3 Achalasia Subtypes

\begin{tabular}{|c|c|c|c|c|}
\hline & Type I $(\mathrm{n}=21)$ & Type II $(\mathrm{n}=28)$ & Type III $(\mathrm{n}=6)$ & $P$-value \\
\hline \multicolumn{5}{|l|}{ Manometric finding } \\
\hline Basal LES pressure (mmHg) & $15.0(8.0-24.0)$ & $26.0(19.0-32.3)^{\mathrm{a}}$ & $39.5(24.8-75.3)^{\mathrm{a}, \mathrm{b}}$ & 0.004 \\
\hline Residual LES pressure $(\mathrm{mmHg})$ & $7.0(2.3-12.8)$ & $4.0(1.0-10.0)$ & $8.0(1.8-10.0)$ & 0.596 \\
\hline Maximal esophageal pressure (mmHg) & $22.0(19.0-27.0)$ & $40.5(37.3-50.0)^{\mathrm{a}}$ & $91.5(69.0-140.5)^{\mathrm{a}, \mathrm{b}}$ & $<0.0001$ \\
\hline Distal esophageal amplitude ( $\mathrm{mmHg})$ & $20.0(17.0-26.0)$ & $38.5(32.3-44.0)^{\mathrm{a}}$ & $74.0(62.5-137.3)^{\mathrm{a}, \mathrm{b}}$ & $<0.0001$ \\
\hline LES overall length (mm) & $23.0(20.0-30.0)$ & $30.0(30.0-40.0)$ & $32.0(23.0-40.5)$ & 0.054 \\
\hline Basal UES pressure ( $\mathrm{mmHg}$ ) & $46.0(21.0-69.5)$ & $35.0(13.3-52.8)$ & $22.0(8.3-45.3)$ & 0.138 \\
\hline $\operatorname{IRP}(\mathrm{mmHg})^{\mathrm{c}}$ & $33.5(21.8-54.0)$ & $28.5(15.3-64.3)$ & $37.5(27.0-33.3)$ & 0.928 \\
\hline Upper endoscopy finding & & & & 0.009 \\
\hline Dilatation or food stasis & $12(60.0)$ & $5(22.7)$ & $0(0.0)$ & \\
\hline Normal & $3(15.0)$ & $10(45.5)$ & $5(83.3)$ & \\
\hline \multicolumn{5}{|l|}{ Esophagogram finding } \\
\hline Maximal esophageal width (mm) & $46.0(35.0-53.0)$ & $37.0(26.3-47.5)$ & $23.0(20.8-26.0)^{\mathrm{a}}$ & 0.010 \\
\hline Bird's beak apperance & $16(80.0)$ & $16(64.0)$ & $0(0.0)$ & 0.006 \\
\hline Normal & $1(5.0)$ & $3(12.0)$ & $2(40.0)$ & \\
\hline
\end{tabular}

${ }^{\mathrm{a}} P<0.05$ vs. type I; ${ }^{\mathrm{b}} P<0.05$ vs. type II; ${ }^{\mathrm{c}}$ only high-resolution manometry procedures $(\mathrm{n}=15)$ were considered.

LES, lower esophageal sphincter; UES, upper esophageal sphincter; IRP, integrated relaxation pressure.

Data are presented as median (interquatile range $[\mathrm{IQR}]$ ) or $\mathrm{n}(\%)$.

Table 3. Good Treatment Response According to Treatment Modality in 3 Achalasia Subtypes

\begin{tabular}{lrrr}
\hline & \multicolumn{3}{c}{ Good treatment response rate $(\mathrm{n}=50)$} \\
\cline { 2 - 4 } & \multicolumn{1}{c}{ Type I } & \multicolumn{1}{c}{ Type II } & Type III \\
\hline $\mathrm{PD}$ & $5 / 7(71.4)$ & $6 / 7(85.7)$ & \\
$\mathrm{LHM}$ & $2 / 4(50.0)$ & $3 / 4(75.0)$ & \\
$\mathrm{CCB}$ & $3 / 5(60.0)$ & $5 / 9(55.6)$ & $5 / 5(100)$ \\
Overall & $10 / 16(62.5)$ & $14 / 20(70.0)$ & $5 / 5(100)$ \\
\hline
\end{tabular}

$\mathrm{PD}$, pneumatic dilatation; LHM, laparoscopic Heller's myotomy; CCB, calcium channel blocker.

Data are presented as $\mathrm{n}(\%)$.

19 patients with type I achalasia, 7 patients (36.8\%) were treated with PD and 4 patients $(21.1 \%)$ were treated with LHM. Among these 11 patients, 5 with PD (71.4\%) and 2 with LHM (50.0\%) achieved good treatment response (Table 3). Of the 26 patients with type II achalasia, 7 patients $(26.9 \%)$ were treated with PD and 4 patients (15.4\%) with LHM. Among these 11 patients, 6 with PD (85.7\%) and 3 with LHM (75.0\%) achieved good treatment response. Five of type I (26.3\%) and 9 of type II achalasia patients $(34.6 \%)$ were treated with calcium channel blocker CCB. The treatment success rate of CCB in type I and II achalasia was $60.0 \%$ and $55.6 \%$, respectively (Table 3 ). In contrast, all type III patients responded to CCB (Table 3 and Fig. $3 \mathrm{~A})$.

\section{Long-term Treatment Response}

Treatment response in 13 patients more than 5 years after the treatment were analyzed. Of the 13 patients, 2 patients who showed good response on PD and LHM relapsed after 5 years and the symptoms of 3 achalasia patients who showed poor response to initial PD or LHM persisted which needed further treatment. Two achalasia patients who were treated with $\mathrm{CCB}$ were followed up with HRM (Fig. 3B). They were diagnosed as having achalasia by CM, 8.7 and 7.4 years ago. Follow-up HRM showed decreased esophageal body pressure compared with previous CM studies (Fig. 4).

\section{Discussion}

The Chicago classification subdivides achalasia into 3 subtypes based on HRM results. In the present study, only 40 of 55 patients $(72.7 \%)$ were diagnosed with achalasia by using CM with a sleeve sensor, because HRM was available from October 2011. The classification of achalasia subtypes based on CM may be less precise than the HRM-based classification. However, Salvador et $\mathrm{al}^{10}$ reported $100 \%$ agreement between the classifications of subtypes based on conventional pressure line tracing versus HRM plots. Moreover, in the European Achalasia Trial, Rohof et $\mathrm{al}^{15}$ also reported similar significant clinical results using $\mathrm{CM}$ with line tracing method. Our results were similar to those 

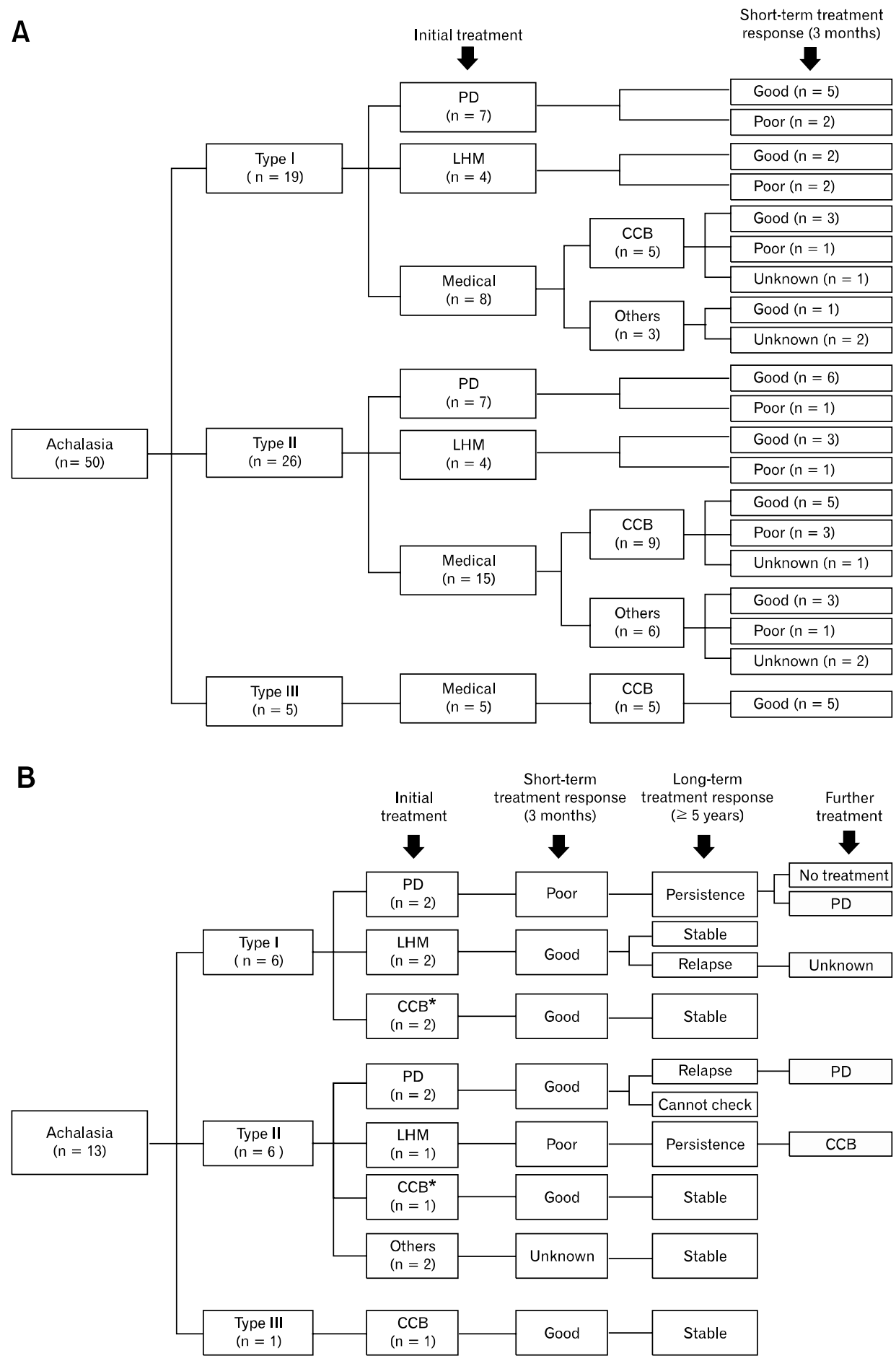

Figure 3. Short-term (3 months) treatment responses of the 50 achalasia patients. Type II achalasia shows good treatment outcomes in pneumatic dilatation (PD; 6/7, 85.7\%) and laparoscopic Heller's myotomy (LHM; 3/4, 75.0\%) in comparison with type I achalasia (5/7, $71.4 \%$ in PD and 2/4, 50.0\% in LHM). All type III achalasia patients responded to calcium channel blocker (CCB) (A). Long-term ( $\geq 5$ years) treatment responses and clinical follow-up of the 13 achalasia patients. Of the 13 patients, 2 patients who showed good response on PD or LHM relapsed after 5 years and the symptoms of 3 achalasia patients who showed poor response to initial PD or LHM persisted which needed further treatment. ${ }^{*}$ Two achalasia patients who were treated with $\mathrm{CCB}$ were followed up with high-resolution manometry (B). Others include proton pump inhibitor, motility drug or antacid. Stable means Eckardt symptom score 3 or less. Relapse means Eckardt symptom more than 3. Good, good response; Poor, poor response.

of other reports $^{9-15}$ in the aspect of clinical, manometric, esophagographic and endoscopic findings. In addition, in 15 achalasia patients who received HRM, the subtyping results based on the amplitude and duration of contractions at 19, 15, 10 and $5 \mathrm{~cm}$ proximal to LES coincided quite well with the HRM results.
Thus, the classification of 3 achalasia subtypes based on CM is comparable with that based on HRM.

In the present study, type II achalasia is suggested to be predominant in Korean achalasia patients. Type II achalasia has been found as the most common type of achalasia in other stud- 

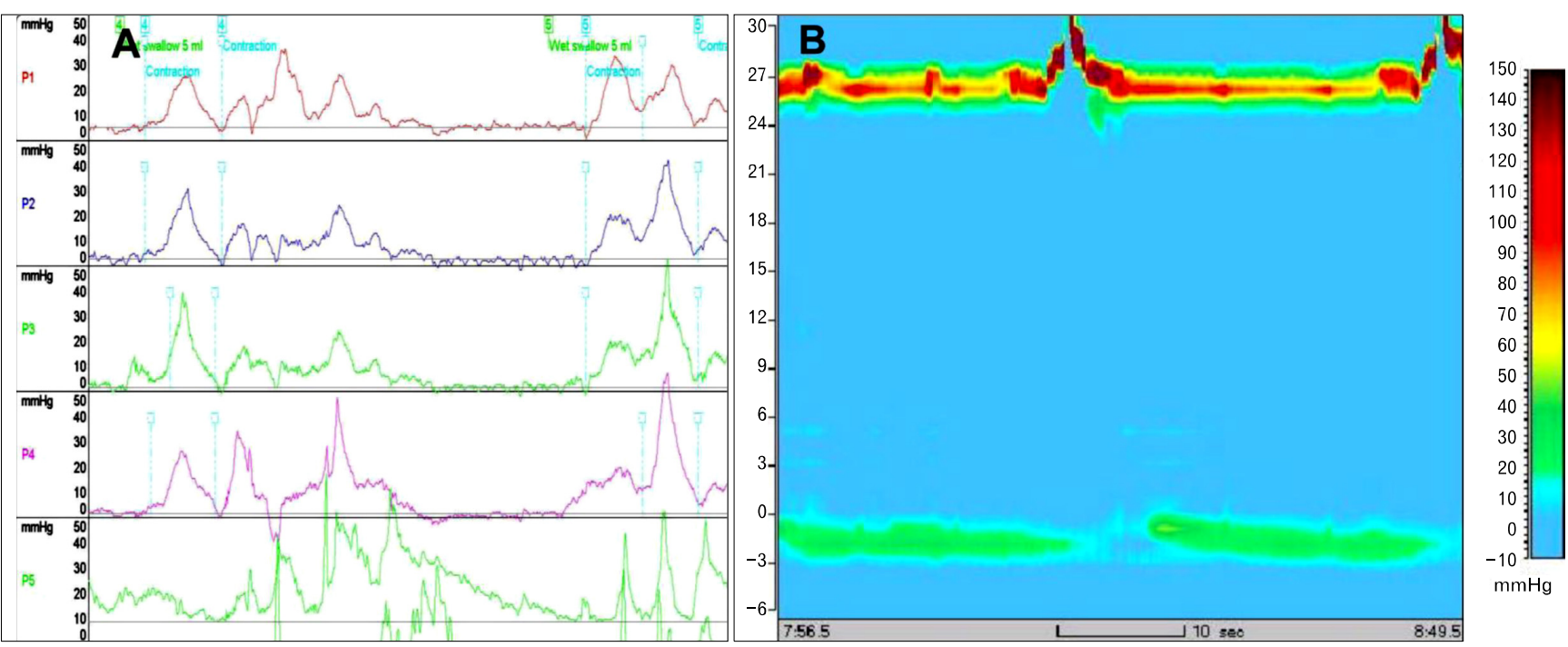

Figure 4. Long-term follow-up monometric finding of anachalasia patient. One 53 year-old woman who complained of dysphagia was diagnosed as having achalasia by conventional manometry (CM), 8.7 years ago. On CM, peak amplitudes 18, 13, 8 and $3 \mathrm{~cm}$ proximal to LES were 26, 25, 32 and $43 \mathrm{mmHg}$, respectively and these findings were compatible with type II achalasia (A). She was recently followed up with high-resolution manometry (HRM). On HRM, the color plot showed a minimal esophageal body pressure below $20 \mathrm{mmHg}$, and HRM findings were compatible with type I achalasia (B). These follow-up results reveal the evidence of esophageal decompensation in this patient. The initial esophagogram showed a standing column of barium with mild passage disturbance inthe distal esophagus; the maximal width of the esophagus was $32.2 \mathrm{~mm}$. A follow-up esophagogram showed more dilated esophagus and a maximal width of $57.3 \mathrm{~mm}$. Upper gastrointestinal endoscopy findings were normal in the initial and follow-up studies.

ies, ${ }^{9,10,12-15}$ except in the one study of an Indian population by Pratap et $\mathrm{al}^{11}{ }^{11}$ in which type I and type II achalasia showed the same frequency (Table 4). Variable causes such as infectious agents, neurodegenerative process, autoimmune factors and genetic susceptibility have been suggested to develop achalasia. Thus, different distributions of races and environmental factors may explain the different frequency of achalasia subtypes in the Indian study. In addition, the age distribution of the 3 subtypes was also different among countries. However, the mean age of type III achalasia was found to be older than the other subtypes in four studies, which is quite similar to our study (Table 4).

In the present study, the evidence of esophageal decompensation was shown on barium esophagogram and upper gastrointestinal endoscopy findings. Pandolfino et $\mathrm{al}^{19}$ nicely presented that the esophagus is flaccid with marked dilatation on the esophagogram in type I achalasia, the proximal esophagus is filled with air in type II achalasia, and the esophagus has an extreme corkscrew appearance, often interpreted as esophageal spasm in type III achalasia. The present study also confirmed that the esophageal width of type I achalasia was larger than that of other subtypes, which was consistent with other studies. ${ }^{10,15}$ Rhee et al ${ }^{20}$ revealed the decompensation process from vigorous achalasia to classic achalasia according to the CM method. Vigorous achalasia represents the acute form with remnant neuromuscular activity in the esophageal body. Further loss of cholinergic neurons, resulting in dilatation and low amplitude simultaneous contractions in the esophageal body is called classic achalasia. According to the Chicago classification, type I and type II with low compression pressure are defined as classic achalasia, and type III and type II with high compression pressure are defined as vigorous achalasia. Pandolfino et $\mathrm{al}^{9}$ suggested that type I and II achalasia could be a continuum of the natural history of the disease, and that type II achalasia may represent a more early stage of the disease. In the present study, 2 achalasia patients showed a decrease in mean body pressure below $20 \mathrm{mmHg}$ in the course of follow-up, and this finding may suggest the progress of type II into type I achalasia, and it could be evidence of esophageal decompensation. However, further large number of follow-up data is needed. Controversy remains with respect to whether these achalasia subtypes correctly represent distinct motor disorders or are simply different points in the progression from a healthy esophagus to end stage achalasia. ${ }^{21}$ However, type III achalasia with higher esophageal pressure and normal upper gastrointestinal endoscopy and normal esophagogram findings, shows poor treatment out- 
Table 4. Subtype, Age Distribution and Treatment Outcomes in Other Studies

\begin{tabular}{|c|c|c|c|c|c|c|}
\hline Study (first author, country) & $\begin{array}{c}\text { Total } \\
\text { patients (n) }\end{array}$ & Subtype & $\begin{array}{l}\text { No. of patients } \\
\quad(\mathrm{n}[\%])\end{array}$ & $\begin{array}{c}\text { Age } \\
(\text { mean } \pm \mathrm{SD}, \mathrm{yr})\end{array}$ & $\begin{array}{l}\text { Treatment } \\
\text { modality }\end{array}$ & Response rate (\%) \\
\hline \multirow{3}{*}{$\begin{array}{l}\text { Pandolfino } \\
\text { USA }\end{array}$} & \multirow[t]{3}{*}{99} & I & $21(21.2)$ & $58.0 \pm 16.9$ & \multirow{3}{*}{$\begin{array}{c}\text { PD, LHM, } \\
\text { Botulinum toxin }\end{array}$} & $56.0^{\mathrm{d}}$ \\
\hline & & II & $49(49.5)$ & $53.4 \pm 19.6$ & & $96.0^{\mathrm{d}}$ \\
\hline & & III & $29(29.3)$ & $63.5 \pm 15.6$ & & $29.0^{\mathrm{d}}$ \\
\hline Salvador ${ }^{10}$ & 246 & I & $96(39.0)$ & $40(28-50)^{\mathrm{a}}$ & \multirow{3}{*}{ LHM } & 84.6 \\
\hline \multirow[t]{2}{*}{ Italy } & & II & $127(51.6)$ & $46(32-58)^{\mathrm{a}}$ & & 95.3 \\
\hline & & III & $23(9.4)$ & $46(30-53)^{\mathrm{a}}$ & & 69.3 \\
\hline Pratap $^{11}$ & 51 & I & $24(47.0)$ & $38.0 \pm 13.5$ & \multirow{3}{*}{$\mathrm{PD}$} & 63.0 \\
\hline \multirow[t]{2}{*}{ India } & & II & $24(47.0)$ & $42.4 \pm 15.2$ & & 90.0 \\
\hline & & III & $3(6.0)$ & $41.0 \pm 15.7$ & & 33.3 \\
\hline $\operatorname{Roman}^{12}$ & 169 & I & $24(14.0)$ & $52(10-88)^{\mathrm{b}}$ & \multirow{3}{*}{ Unavailable } & \\
\hline \multirow[t]{2}{*}{ France } & & II & $118(70.0)$ & $52(11-90)^{\mathrm{b}}$ & & \\
\hline & & III & $27(16.0)$ & $62(14-93)^{b}$ & & \\
\hline \multirow{3}{*}{$\begin{array}{l}\operatorname{Min}^{13} \\
\text { China }\end{array}$} & 75 & I & $25(33.0)$ & $45.3 \pm 13.1$ & \multirow{3}{*}{$\begin{array}{c}\text { PD, LHM, } \\
\text { Botulinum toxin }\end{array}$} & $23.8^{\mathrm{e}}$ \\
\hline & & II & $46(61.0)$ & $42.3 \pm 15.4$ & & $67.6^{\mathrm{e}}$ \\
\hline & & III & $4(5.0)$ & $60.0 \pm 15.6$ & & $0.0^{\mathrm{e}}$ \\
\hline \multirow{3}{*}{$\begin{array}{l}\text { Yamashita }^{14} \\
\text { Japan }\end{array}$} & 25 & I & $6(24.0)$ & $43.6(23-75)^{\mathrm{c}}$ & \multirow{3}{*}{$\mathrm{PD}$} & 100.0 \\
\hline & & II & $15(60.0)$ & $51.5(25-84)^{c}$ & & 100.0 \\
\hline & & III & $4(16.0)$ & $60.2(23-88)^{\mathrm{c}}$ & & 66.6 \\
\hline \multirow{3}{*}{$\begin{array}{l}\text { Rohof }^{15} \\
\text { European Achalasia Trial }\end{array}$} & 176 & I & $44(25.0)$ & $44.0 \pm 2.4$ & \multirow{3}{*}{ PD, LHM } & $85.7(81.0)^{\mathrm{f}}$ \\
\hline & & II & $114(64.7)$ & $46.0 \pm 1.4$ & & $100.0(95.0)^{\mathrm{f}}$ \\
\hline & & III & $18(10.2)$ & $49.0 \pm 3.4$ & & $40.0(86.0)^{\mathrm{f}}$ \\
\hline
\end{tabular}

${ }^{a, c}$ Median (interquartile range [IQR]); ${ }^{b}$ Mean (range); ${ }^{\mathrm{d}}$ Success after last intervention (botulinum toxin injection, pneumatic dilatation [PD] or laparoscopic Heller's myotomy [LHM] were performed as the first intervention; a second dilatation with larger balloon or LHM were performed as the last intervention); ${ }^{\mathrm{e} B}$ otulinum toxin or PD or LHM; ${ }^{f}$ Data represent PD (LHM).

comes in PD and LHM. ${ }^{9,10,15}$ Furthermore, as the mean age of type III achalasia is older than the other subtypes, the possibility that type III achalasia represents an early stage of the disease is low.

Among the 3 subtypes of achalasia, longitudinal muscle contraction and sufficient circular muscle excitation are preserved in type II achalasia, sustaining some degree of esophageal body compression. ${ }^{22}$ Therefore, type II achalasia shows good treatment response by LES pressure reduction. On the other hand, in type III achalasia, both circular and longitudinal muscles contract, but there is severe discoordination between the 2 muscle layers. ${ }^{23}$ Interestingly, the total Eckardt score of type III achalasia was lower than the that of other types even though there was no statistical significance. Furthermore, all of them showed good response to CCB. Another study also showed that type III achalasia patients responded to neuromodulators, such as tricyclic antidepressants. ${ }^{24}$ So far, the main treatment option of type III achalasia has focused on the inhibition of the spasm, ${ }^{19,25}$ but the further large studies are needed to prove this theory.

The limitations of this study are as follows: first, treatment options, timing of treatment and follow-up period in each patient were different because this is a retrospective study, although all the enrolled patient's symptoms were recorded by the same planned description format. Second, this study has a limitation stemming from its small sample size.

In conclusion, type II achalasia is the most common subtype in present study for the Korean population. Type I achalasia may represent a later stage of type II achalasia. Type III was rather rare, mainly found in the elderly and relatively responsive to medical therapy, and these findings suggest that it should be a different entity from those of type I and II.

\section{References}

1. Mayberry JF. Epidemiology and demographics of achalasia. Gastrointest Endosc Clin N Am 2001;11:235-248.

2. Richter JE. Achalasia - an update. J Neurogastroenterol Motil 2010;16:232-242.

3. Ghoshal UC, Daschakraborty SB, Singh R. Pathogenesis of achalasia cardia. World J Gastroenterol 2012;18:3050-3057.

4. Park W, Vaezi MF. Etiology and pathogenesis of achalasia: the current understanding. Am J Gastroenterol 2005;100:1404-1414. 
5. Fox M, Hebbard G, Janiak P, et al. High-resolution manometry predicts the success of oesophageal bolus transport and identifies clinically important abnormalities not detected by conventional manometry. Neurogastroenterol Motil 2004;16:533-542.

6. Pandolfino JE, Ghosh SK, Rice J, Clarke JO, Kwiatek MA, Kahrilas PJ. Classifying esophageal motility by pressure topography characteristics: a study of 400 patients and 75 controls. Am J Gastroenterol 2008;103:27-37.

7. Carlson DA, Pandolfino JE. The Chicago criteria for esophageal motility disorders: what has changed in the past 5 years? Curr Opin Gastroenterol 2012;28:395-402.

8. Kahrilas PJ. Esophageal motor disorders in terms of high-resolution esophageal pressure topography: what has changed? Am J Gastroenterol 2010;105:981-987.

9. Pandolfino JE, Kwiatek MA, Nealis T, Bulsiewicz W, Post J, Kahrilas PJ. Achalasia: a new clinically relevant classification by high-resolution manometry. Gastroenterology 2008;135:1526-1533.

10. Salvador R, Costantini M, Zaninotto G, et al. The preoperative manometric pattern predicts the outcome of surgical treatment for esophageal achalasia. J Gastrointest Surg 2010;14:1635-1645.

11. Pratap N, Kalapala R, Darisetty S, et al. Achalasia cardia subtyping by high-resolution manometry predicts the therapeutic outcome of pneumatic balloon dilatation. J Neurogastroenterol Motil 2011;17: 48-53.

12. Roman S, Zerbib F, Queneherve L, Clermidy H, Varannes SB, Mion F. The Chicago classification for achalasia in a French multicentric cohort. Dig Liver Dis 2012;44:976-980.

13. Min M, Peng LH, Yang YS, et al. Characteristics of achalasia subtypes in untreated Chinese patients: a high-resolution manometry study. J Dig Dis 2012;13:504-509.

14. Yamashita H, Ashida K, Fukuchi T, et al. Predictive factors associated with the success of pneumatic dilatation in Japanese patients with primary achalasia: a study using high-resolution manometry.
Digestion 2013;87:23-28.

15. Rohof WO, Salvador R, Annese V, et al. Outcomes of treatment for achalasia depend on manometric subtype. Gastroenterology 2013; 144:718-725.

16. Eckardt VF. Clinical presentations and complications of achalasia. Gastrointest Endosc Clin N Am 2001;11:281-292, vi.

17. Vantrappen G, Hellemans J, Deloof W, Valembois P, Vandenbroucke J. Treatment of achalasia with pneumatic dilatations. Gut 1971; 12:268-275.

18. Boeckxstaens GE. Achalasia. Best Pract Res Clin Gastroenterol 2007;21:595-608.

19. Pandolfino JE, Kahrilas PJ. Presentation, diagnosis, and management of achalasia. Clin Gastroenterol Hepatol 2013;11:887-897.

20. Rhee K, Jeon H, Kim JH, Yoon YH, Park H, Lee SI. An evidence of esophageal decompensation in patients with achalasia in the view of its subtype: a retrospective study. J Neurogastroenterol Motil 2013; 19:319-323.

21. Scherer JR, Kwiatek MA, Soper NJ, Pandolfino JE, Kahrilas PJ. Functional esophagogastric junction obstruction with intact peristalsis: a heterogeneous syndrome sometimes akin to achalasia. J Gastrointest Surg 2009;13:2219-2225.

22. Hong SJ, Bhargava V, Jiang Y, Denboer D, Mittal RK. A unique esophageal motor pattern that involves longitudinal muscles is responsible for emptying in achalasia esophagus. Gastroenterology 2010;139:102-111.

23. Mittal RK, Hong SJ, Bhargava V. Longitudinal muscle dysfunction in achalasia esophagus and its relevance. J Neurogastroenterol Motil 2013;19:126-136.

24. Kushnir V, Sayuk GS, Gyawali CP. Multiple rapid swallow responses segregate achalasia subtypes on high-resolution manometry. Neurogastroenterol Motil 2012;24:1069, e561.

25. Roman S, Kahrilas PJ. Management of spastic disorders of the esophagus. Gastroenterol Clin North Am 2013;42:27-43. 